\title{
Correction to: Financing Our Future
}

\section{Correction to:}

\section{S. Brunnhuber, Financing Our Future, https://doi.org/10.1007/978-3-030-64826-8_7}

This book was inadvertently published without updating the following corrections:

Abbreviations:

p. = page

Corrections:

p. vii: Keep the epigraph before 'Dedication' in p.v

p. ix, xi, xiii, xv, xvii, xix: remove epigraphs

p. xxiii: 'The TAO of Finance Team' - Change to heading level-1.

p. xli: Replace 'Introduction' with 'What This Book Is All About: FinanceFuture-Balance and the Rest'.

p. xxv: Correct 'The Academy' title.

p. xxv: Move 'Impressum' to left lower corner in same page

p. $33,52,68,76,84,88,123,164,177$, and 185: Set pull quotes in Box without heading. 
p. 125: Correct the second black arrow in Graph 5.2.

p. 139: Remove the lettering in Graph 5.6.

p. 144: Correct big and small green arrows in Graph 5.8-b.

p. 115, note 16: Remove hyphen after 'sustain' in the link - https://sustain-

p. 158, note 40: Remove hyphen after 'new' in the link - http://new-

p. 161 , note 66: Remove hyphen after 'three' in the link - https://three- 